\title{
Influenza vaccination of primary healthcare physicians may be associated with vaccination in their patients: a vaccination coverage study
}

Pere Godoy ${ }^{1,2,3^{*}}$, Jesús Castilla ${ }^{2,4 \dagger}$, José María Mayoral ${ }^{5 \dagger}$, Vicente Martín ${ }^{2,6+}$, Jenaro Astray ${ }^{7 \dagger}$, Núria Torner ${ }^{1,2,8+}$, Diana Toledo ${ }^{2,8,9+}$, Núria Soldevila2,8+ ${ }^{2, F e r n a n d o ~ G o n z a ́ l e z-C a n d e l a s ~}{ }^{2,10 \dagger}$, Susana García ${ }^{11+}$, José Diaz-Borrego ${ }^{12 \dagger}$, Sonia Tamames ${ }^{13+}$, Angela Domínguez ${ }^{2,8+}$ and the Working Group for the Survey on Influenza Vaccination in Primary Health Care Professionals

\begin{abstract}
Background: To assess the contribution of physician-related factors, especially their influenza vaccine status, in the vaccination coverage of their patients.

Methods: A study of vaccination coverage was carried out in Spain in 2011-12. The dependent variable (vaccination coverage in patients aged $\geq 65$ years) was obtained from regional records. Information was gathered on the vaccination of physicians through an anonymous web survey. We compared the vaccination coverage of patients with the vaccination of their physicians using the Student $t$ test. Associations were determined using a multilevel regression model.
\end{abstract}

Results: The coverage in patients aged $\geq 65$ years was $56.3 \%$ and was higher (57.3\%) in patients whose physician had been vaccinated than in those whose physician had not (55.2\%) $(p=0.008)$. In the multilevel regression model, vaccination of the physician was associated $(p=0.049)$ with vaccination of their patients after controlling for the effects of age $(p=0.046)$, region $(p=0.089)$, and opinions on the effectiveness of the vaccine $(p=0.013)$.

Conclusions: Vaccination of physicians together with their opinions on the effectiveness of the vaccine may be a predictor of vaccination coverage in their patients. Further studies are required to confirm this.

Keywords: Vaccine, Influenza, Physician, Coverage, Elderly

\section{Background}

Influenza is a highly-contagious disease that causes a significant disease burden [1] and is estimated to affect 5$15 \%$ of the world population annually [2]. Health care workers $(\mathrm{HCW})$ may be exposed to the influenza virus in the workplace and can also act as a source of infection of patients and health authorities therefore recommend annual vaccination $[1,3-6]$. However, although there is evidence on the effectiveness of influenza vaccination, some Spanish [4-7] and international [8-11] studies show that coverages do not generally exceed $40 \%$.

\footnotetext{
* Correspondence: pere.godoy@gencat.cat

${ }^{\dagger}$ Equal contributors

'Agencia de Salud Pública de Cataluña, Barcelona, Spain

${ }^{2}$ CIBER Epidemiología y Salud Pública (CIBERESP), Barcelona, Spain

Full list of author information is available at the end of the article
}

Influenza vaccination has been shown to be effective in protecting the elderly and reducing morbidity and mortality in both institutionalized and community dwellers $[12,13]$. Therefore, vaccination is generally recommended in this population group [1].

Studies have shown the importance of physicians recommending vaccination to their community-dwelling patients $[14,15]$. Likewise, an association has been shown between effective vaccination of physicians and the effectiveness of their recommendations to their patients: physicians who are vaccinated have a greater capacity to effectively counsel their patients $[16,17]$.

A weaker and more controversial association between vaccination of primary care physicians and real vaccination of their patients has also been suggested [18]. 
Primary care physicians are in direct contact with the population and therefore their views on influenza vaccine and the decision to vaccinate may be determining factors in the vaccination of their patients $[17,19,20]$. In Spain, influenza vaccination is offered free of charge to groups in which it is indicated, including healthcare workers and persons aged $\geq 65$ years, in primary healthcare centers after prescription by the patient's physician. Vaccination is offered in October and November, in a similar fashion to most European countries [21].

The aim of this study was to assess the contribution of physician-related factors, especially their influenza vaccine status, in the vaccination coverage of their patients aged $\geq 65$ years.

\section{Methods}

We conducted an epidemiological study of the prevalence of influenza vaccination coverage in patients aged $\geq 65$ and influenza vaccination of primary care physicians according to the Strengthening the Reporting of Observational Studies in Epidemiology (STROBE) statement (guidelines for reporting observational studies) [22]. Of a total of 1791 primary care centers, we randomly selected 253 in seven Spanish regions (Andalusia, Castile-Leon, Catalonia, Valencia, Madrid, Navarre and Basque Country) in the 2011-12 season. A questionnaire was administered anonymously to physicians working in these centers between March 1 and May 25, 2012, via the internet, to obtain information on the main independent variable (influenza vaccination of primary care physician) and other variables (age, gender, education, opinions and attitudes of primary care physicians to influenza vaccination).

The questionnaire was developed after reviewing the scientific literature on the subject, especially the questionnaire used in the study by Kraut et al. [11]. The questions were adapted to the specific circumstances of the Spanish National Health System and two pilot tests were conducted among medical staff in the researchers' settings to validate understanding of the questionnaire and its length. The final questionnaire consisted of 23 questions (22 closed and one open). Questions were distributed in three sections: information on the history of chronic disease and vaccination, knowledge of influenza and the influenza vaccine, and sociodemographic information. The questions were structured to appear gradually, spread over a total of six screens. The first screen welcomed the participants and provided general information on the survey. The following four screens contained the survey questions, and the last screen contained a text thanking the participants. Using the tools provided by the web platform, 19 of the 23 questions were compulsory, i.e., they had to be answered in order to access the following question.

\section{Study subjects}

The target population was any physician providing direct patient care in primary healthcare centers. In these centers, influenza vaccination is administered without cost by nurses to all population groups for which it is indicated, including people aged $\geq 65$ years, according to physician prescription. Participating centers were randomly selected from a list of the centers in each region. All physicians in each center who had an email address were initially included. The questionnaire was accessible for a month and an email reminder was sent every 10 days to physicians who had not accessed the questionnaire or had not completed the survey.

\section{Variables}

The following variables were collected: profession, age, and sex. We also collected the presence of contraindications to influenza vaccination in each $\mathrm{HCW}$, influenza vaccination in the 2011-2012 season and information on physicians' knowledge of and opinions and attitudes to influenza and influenza vaccination. Variables related to knowledge of and attitudes to influenza vaccination were covered by a set of questions evaluated on a Likert scale with 5 categories: totally agree, agree quite a lot, neither agree nor disagree, disagree quite a lot, and totally disagree. Information on the dependent variable (vaccination coverage in patients aged $\geq 65$ years treated by physicians who participated in the study) was obtained from regional primary care records and was included as study information associated with each individual physician survey.

\section{Statistical analysis}

The data analysis included physicians providing direct patient care in primary care centers who reported information about their vaccination in the 2011-2012 season and in whom we could recover vaccination uptake in their patients aged $\geq 65$ years. Physicians in whom vaccination was contraindicated were excluded.

The researchers responsible for each region facilitated listings of the HCW from each center containing the e mail address patients ascribed to each physician and vaccination coverage in their patients aged $\geq 65$ years. The Coordinator Center received all lists and formulated a new list which assigned a number corresponding to each participant. This numbering was used to anonymize listings. The new listing was loaded on the web platform. At the end survey period, a database of completed surveys was extracted and was cross-checked with the anonymized list to identify non-responders. To characterize nonanswers, we obtained information from $49.1 \%$ of physicians who did not respond to the survey. Physicians who responded to the survey were compared to those who did not according to physicians' age and sex and vaccination coverage in their patients aged $\geq 65$ years. 
The answers to questions about knowledge and attitudes were dichotomized in two categories: positive (totally agree, agree quite a lot) and negative (neither agree nor disagree, disagree quite a lot, and totally disagree).

A bivariate comparison using the Chi-square test was made in vaccinated/unvaccinated physicians considering the different sociodemographic variables and the answers to questions about knowledge and attitudes. Vaccination coverage in patients aged $\geq 65$ years was compared with the main independent study variables using the Student's $t$ test.

The association between vaccination coverage in patients aged $\geq 65$ years and the main independent variable (vaccination of their physicians) was determined using a multilevel regression model with input of variables with a significance of $\mathrm{p}<0.10$. All statistical tests were two-tailed and the $\alpha$ error accepted was 0.05 . The analysis was performed using SPSS version 18 (SPSS Inc., Chicago, IL).

\section{Ethical considerations}

All information collected was treated in strict observance of legislation on observational studies. The study protocol was approved by the Ethics and Clinical Research Committee of the Jordi Gol Institute for Research in Primary Care.

\section{Results}

The survey was sent to 2535 primary care physicians, of whom 1292 (51.0\%) initiated the survey and 872 completed it (34.4\%). Physicians who did not respond to the survey were more frequently aged $>55$ years $(67.0 \%$, $229 / 342, p=0.003$ ), but no statistically-significant differences were observed for sex $(p=0.479)$ or vaccination coverage of patients aged $\geq 65$ years $(\mathrm{p}=0.146)$.

Twenty-five physicians who responded to the survey had contraindications to influenza vaccine and 32 did not have valid information on coverage in patients aged $\geq 65$ years. Therefore, 815 physicians were finally analyzed, of which $58.4 \%(476 / 815)$ were female. The main age groups were $45-54$ years $(44.7 \%, 364 / 815)$ and $55-64$ years $(26.4 \%, 215 / 815)$. A total of $38.7 \%$ of participating physicians $(315 / 815)$ reported having received specific training, $67.2 \%(548 / 815)$ believed that influenza could be a serious illness, $59.4 \%(484 / 815)$ were concerned about infecting their patients, $87.4 \%(712 / 815)$ believed that the vaccine was effective and $49.8 \%$ (406/ 815) were worried about becoming ill due to influenza (Table 1).

Influenza vaccination coverage in participating physicians was $55.3 \%(451 / 815)$, and was higher in those aged $45-54$ years $(58.5 \%, 213 / 364)$ and $55-64$ years $(55.8 \%$, $120 / 215)$, in males $(57.8 \%, 196 / 339)$, in those who had received prior training on influenza $(56.8 \%, 179 / 315)$ and in those who believed that influenza was a serious illness
Table 1 Characteristics of primary care physicians who responded to the survey, Spain, 2012

\begin{tabular}{|c|c|c|}
\hline Variables & $\%$ & $n / N$ \\
\hline \multicolumn{3}{|l|}{ Sex: } \\
\hline Female & 58.4 & $476 / 815$ \\
\hline Male & 41.6 & $339 / 815$ \\
\hline \multicolumn{3}{|l|}{ Age (years) } \\
\hline $25-34$ & 3.3 & $27 / 815$ \\
\hline $35-44$ & 25.6 & $209 / 815$ \\
\hline $45-54$ & 44.7 & $364 / 815$ \\
\hline $55-64$ & 26.4 & $215 / 815$ \\
\hline \multicolumn{3}{|c|}{ Participates in the influenza sentinel system } \\
\hline Yes & 11.4 & $93 / 815$ \\
\hline No & 88.6 & $722 / 815$ \\
\hline \multicolumn{3}{|c|}{ Training activities on influenza } \\
\hline Yes & 38.7 & $315 / 815$ \\
\hline No & 61.3 & $500 / 815$ \\
\hline \multicolumn{3}{|c|}{ I believe that influenza may be a severe illness } \\
\hline Yes & 67.2 & $548 / 815$ \\
\hline No & 32.8 & $267 / 815$ \\
\hline \multicolumn{3}{|c|}{ I worry about infecting my patients } \\
\hline Yes & 59.4 & $484 / 815$ \\
\hline No & 40.6 & $331 / 815$ \\
\hline \multicolumn{3}{|c|}{ I believe the influenza vaccine is effective } \\
\hline Yes & 87,4 & $712 / 815$ \\
\hline No & 12.6 & $103 / 815$ \\
\hline \multicolumn{3}{|c|}{ I worry about becoming ill due to influenza } \\
\hline Yes & 49.8 & $406 / 815$ \\
\hline No & 50.2 & $409 / 815$ \\
\hline
\end{tabular}

(56.9, 312/548), although the differences were not statistically-significant (Table 2), and was significantly higher in physicians who were worried about infecting their patients $(69.6 \%, 337 / 484 ; \mathrm{p}<0.001)$, in those who thought that the vaccine was effective $(60.1 \%, 428 / 712$; $\mathrm{p}<0.001)$, and in those concerned about becoming ill due to influenza $(77.1 \%, 313 / 406 ; \mathrm{p}<0.001)$ (Table 2).

The mean coverage of patients aged $\geq 65$ years ascribed to participating physicians was $56.3 \%$ (range $10.1 \%$ to $92.5 \%)$. The coverage was higher in patients whose physicians had received influenza vaccination (57.3\%) than in those whose physicians had not (55.2\%) $(p=0.008)$. Coverages were also higher in patients whose physician was aged $<55$ years $(56.7 \%)$ than in those whose physician was aged $\geq 55$ years $(55.2 \%)(\mathrm{p}=0.067)$. With respect to physicians' attitudes, opinions and knowledge, the only variable associated with increased vaccination coverage in their patients was considering that influenza vaccination was effective (56.8\%) compared with 
Table 2 Prevalence of influenza vaccination in primary care physicians according to study variables, Spain, 2012

\begin{tabular}{llll}
\hline $\begin{array}{l}\text { Characteristics of } \\
\text { primary care physicians }\end{array}$ & $\begin{array}{l}\text { Prevalence of } \\
\text { vaccination \% }\end{array}$ & $\mathrm{n} / \mathbf{N}$ & $\mathbf{p}^{\mathbf{a}}$ \\
\hline Total & $\mathbf{5 5 . 3}$ & $\mathbf{4 5 1 / 8 1 5}$ & \\
Sex: & & & \\
$\quad$ Female & 53.6 & $255 / 476$ & 0.129 \\
$\quad$ Male & 57.8 & $196 / 339$ &
\end{tabular}

Age (years)

$25-34$

$35-44$

$45-54$

$55-64$

Participates in the influenza sentinel system

Yes
No

Training activities on influenza

$$
\text { Yes }
$$$$
\text { No }
$$

37.0
51.7
58.5
55.8

$\begin{array}{ll}10 / 27 & 0.098 \\ 108 / 209 & \\ 213 / 364 & \\ 120 / 215 & \end{array}$

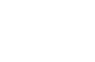

$\begin{array}{ll}51 / 93 & 0.918 \\ 400 / 722 & \end{array}$

I believe that influenza

may be a severe illness

$\begin{array}{llll}\text { Yes } & 56.9 & 312 / 548 & 0.189 \\ \text { No } & 52.1 & 139 / 267 & \end{array}$

I worry about infecting my patients

$$
\text { Yes }
$$$$
\text { No }
$$

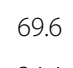

$$
\begin{aligned}
& 69.6 \\
& 34.4
\end{aligned}
$$$$
337 / 484<0.001
$$

I believe the influenza vaccine is effective

\begin{tabular}{llll} 
Yes & 60.1 & $428 / 712<0.001$ \\
No & 22.3 & $23 / 103$ & \\
worry about becoming & & & \\
$\begin{array}{l}\text { ill due to influenza } \\
\text { Yes }\end{array}$ & 77.1 & $313 / 406<0.001$ \\
No & 33.7 & $138 / 409$ & \\
\hline
\end{tabular}

$a_{p}$ value.

patients whose physician felt that it was not (53.5\%) (p <0.005) (Table 3).

In the multilevel regression analysis, a physician's history of receiving influenza vaccination was associated with the vaccination of their patients aged $\geq 65$ years $(\mathrm{p}=0.049)$, after controlling for the effect of age $(\mathrm{p}=$ $0.046)$, region $(p=0.089)$, opinions on the effectiveness of the vaccine $(p=0.013)$, concern about infecting their patients $(p=0.071)$ and concern about becoming ill from influenza $(\mathrm{p}=0.652)($ Table 4$)$.

\section{Discussion}

Influenza vaccination coverage in patients aged $\geq 65$ years varied widely, but was within the ranges found by other
Table 3 Influenza vaccination coverage in patients aged $\geq 65$ years according to the characteristics of their primary care physician, Spain, 2012

\begin{tabular}{llll}
\hline $\begin{array}{l}\text { Characteristics } \\
\text { of primary } \\
\text { care physicians }\end{array}$ & $\begin{array}{l}\text { Mean vaccination } \\
\text { coverage in patients } \\
\text { aged } \geq \mathbf{6 4} \text { years }\end{array}$ & $\begin{array}{l}\mathbf{9 5 \%} \\
\text { Confidence } \\
\text { intervals }\end{array}$ & $\mathbf{P}^{\mathbf{a}}$ \\
\hline $\begin{array}{l}\text { Total } \\
\text { Influenza vaccination }\end{array}$ & $\mathbf{5 6 . 3}$ & $\mathbf{5 5 . 6}-\mathbf{5 7 . 1}$ & \\
$\quad$ Yes & 57.3 & $56.2-58.3$ & 0.008 \\
$\quad$ No & 55.2 & $54.1-56.2$ & \\
$\begin{array}{l}\text { Sex: } \\
\text { Female }\end{array}$ & 56.6 & $55.7-57.5$ & 0.448 \\
$\quad$ Male & 56.0 & $54.7-57.2$ & \\
Age (years) & & & \\
$25-34$ & 57.3 & $53.6-61.0$ & 0.330 \\
$35-44$ & 56.7 & $55.1-58.2$ & \\
$45-54$ & 56.8 & $55.7-57.8$ & \\
$55-64$ & 55.2 & $53.6-56.8$ & \\
$\begin{array}{l}\text { Participates in the } \\
\text { influenza sentinel system }\end{array}$ & & & 0.585 \\
Yes & 55.8 & $53.9-57.6$ & \\
No & 56.4 & $55.6-57.2$ &
\end{tabular}

Training activities

on influenza

$\begin{array}{lll}\text { Yes } & 57.0 & 55.9-58.0 \\ \text { No } & 56.0 & 54.9-57.0\end{array}$

I believe that influenza may be a severe illness

$\begin{array}{llll}\text { Yes } & 56.5 & 55.9-57.4 & 0.639 \\ \text { No } & 56.1 & 54.7-57.5 & \end{array}$

I worry about infecting my patients

\begin{tabular}{llll} 
Yes & 56.0 & $55.1-57.0$ & 0.321 \\
No & 56.8 & $55.5-58.0$ & \\
$\begin{array}{l}\text { believe the influenza } \\
\text { vaccine is effective }\end{array}$ & & & \\
Yes & 56.8 & $56.0-57.5$ & 0.005 \\
No & 53.5 & $51.2-55.9$ & \\
$\begin{array}{l}\text { worry about becoming } \\
\text { due to influenza }\end{array}$ & & & \\
Yes & 54.8 & $54.0-55.7$ & 0.912 \\
No & 54.7 & $53.9-55.5$ & \\
\hline
\end{tabular}

${ }^{a} p$ value.

studies in Spain [23,24] and Europe [8,21], and was associated with the vaccination of their primary care physician, after controlling for the possible effects of physicians knowledge, opinions and attitudes towards influenza. Likewise, vaccination of primary care physicians (55.3\%) was higher than that found in other Spanish [4-7] and international [8-10,21] studies. 
Table 4 Factors in primary care physicians associated with influenza vaccination of their patients aged $\geq 65$ years in the multilevel regression model, Spain, 2012

\begin{tabular}{|c|c|c|c|c|c|}
\hline \multirow{2}{*}{$\begin{array}{l}\text { Characteristics of primary care physicians } \\
\text { Fixed effects }\end{array}$} & \multirow[t]{2}{*}{ Regression coefficient $\beta$} & \multicolumn{2}{|c|}{ Regression coefficient $\beta$ 95\% $\mathrm{Cl}^{\mathrm{a}}$} & \multirow[t]{2}{*}{$t^{b}$} & \multirow[t]{2}{*}{$p^{c}$} \\
\hline & & & & & \\
\hline Constant & 53.526 & 49.828 & 57.225 & 30.215 & 0.000 \\
\hline Influenza vaccination (1.Yes; 0.No) & 1.650 & .005 & 3.295 & 1.969 & .049 \\
\hline Age $(1.55+; 0 .<55$ years $)$ & 1.675 & .031 & 3.319 & 2.000 & .046 \\
\hline I believe the influenza vaccine is effective ( 1. Yes; $0 . \mathrm{No}$ ) & 2.866 & .596 & 5.136 & 2.478 & .013 \\
\hline I worry about infecting my patients (1.Yes; 0.No) & -1.579 & -3.292 & .134 & -1.809 & .071 \\
\hline I worry about becoming ill due to influenza (1.Yes; 0.No) & -.401 & -2.142 & 1.341 & -.451 & .652 \\
\hline
\end{tabular}

\section{Random effects}

Spanish regions ${ }^{d}$, Estimated variance

$11.829 \pm 6.952(p=0.089)$

${ }^{a}$ Confidence interval.

$b_{t}$ value.

cp value.

${ }^{\mathrm{d} S p a n i s h}$ regions: Andalusia, Castile-Leon, Catalonia, Valencia, Madrid, Navarre and Basque Country.

Both vaccine coverages were far from the European targets for HCW and the elderly [21] and may have been overestimated due to a possible bias caused by a greater response to the survey from physicians with a better vaccination record. We compared the characteristics of early and late responders to the survey as a proxy for non-responders: no differences were found according to age and sex, but influenza vaccine coverage in patients aged $\geq 65$ years was higher for physicians who were early responders (Additional file 1: Table S1).

The vaccine influenza coverage in patients aged $\geq$ 65 years was quite similar to the figures of the Spanish Health Ministry [21], but the coverage in regions participating in the study was slightly higher than in the remaining Spanish regions (Additional file 1: Table S2) [25].

The highest reported European vaccination coverages in patients aged $\geq 65$ years are in the Netherlands and some parts of the UK (England, Northern Ireland and Scotland), which reached or almost reached the EU 2014/15 target. Five countries (France, Germany, Ireland, Italy and Spain) reported vaccination coverages of around $60 \%$ for this specific age group. Denmark, Finland, Luxembourg, Malta, Norway, Portugal and Sweden reported vaccination coverages of around $50 \%$. The remaining countries were below 50\% [21].

The study had some other limitations. The response rate of primary care physicians was low, although similar to that of other studies conducted using web-based questionnaires $[11,26-28]$. As the questionnaire was selfreported, it was not possible to validate the questions or use interviewers to clarify any disputed points. However, the questionnaire was adapted to the Spanish health system according to a questionnaire used in another study [11]. In addition, a pilot study was carried out. Information on vaccination coverage was collected from the records of healthcare providers for all patients ascribed to each physician in the form of clusters and, therefore, the estimate was not controlled according to the individual variables of each vaccinated patient.

The results of the study provide some relevant information. The effect of vaccination of the primary care physician was a minor determinant of the vaccination coverage of their patients aged $\geq 65$ years $(57.3 \%$ versus $55.2 \%$ ), but remained statistically-significant after controlling for other potential effects associated with the physician's knowledge, attitudes and beliefs on influenza vaccination. The $2 \%$ increase in coverage, although moderate, should be considered positively, as it relates to physicians in direct contact with the majority of the population [10]. In addition, the advantage conferred by being associated with an intervention (vaccination of physicians) that may reduce the transmission of influenza to vulnerable patients [8] and possibly increase the physician's confidence in providing counseling on vaccination, should be taken into account [16]. Some studies suggest that medical advice has greater efficacy if it comes from vaccinated physicians [16,29].

Vaccination of patients aged $\geq 65$ years was also associated in the multilevel regression model with physicians having a favorable opinion of vaccine effectiveness. This variable has been associated with improved vaccination coverage in other studies [11,30-34] and should be taken into account in educational programs aimed at primary care physicians whose objective is to improve vaccination coverages. However, vaccination of patients was not associated with a higher level of knowledge of their physicians provided by training activities. Therefore, any intervention programs aimed at Spanish primary care Spain should be directed towards improving opinions and attitudes about vaccination rather than trying to increase knowledge.

Interventions to increase influenza vaccination rates in HCW have shown small effects on vaccination behavior, 
and their long-term success is unknown. Kok et al. [35] suggested that a systematic approach (i.e. intervention mapping) is needed for the successful development and implementation of programs to promote influenza vaccination in $\mathrm{HCW}$, identifying sociocognitive variables that drive the recommended behavior. Other studies show that having a mandatory vaccination policy is the strongest predictor of vaccine coverages in $\mathrm{HCW}$ and that implementing such a policy should be a priority for all healthcare agencies [36-38]. In the absence of or in conjunction with a mandatory vaccination policy, other interventions may be implemented to increase vaccination compliance in HCW. These include reducing barriers to vaccination, encouraging staff to be vaccinated, and introducing educational campaigns [36,39], all of which suggest the need for healthcare administrators to be active in encouraging vaccination in HCW. Healthcare agencies should provide free vaccination on site to their staff whenever possible to increase compliance $[36,39]$. This is even more critical in nonhospital settings. Educational campaigns based on beliefs aligned with scientific evidence and more favorable attitudes toward vaccines can also improve the intent of $\mathrm{HCW}$ to be vaccinated.

There is sufficient evidence that increases in the vaccination of people aged $\geq 65$ years leads to a reduction in mortality and morbidity in both institutionalized $[13,40]$ and community-dwelling $[12,40]$ patients. In addition, clinical trials show it is feasible to increase the vaccination of primary care physicians. A clinical trial by Abramson et al. [18] found that vaccination coverage in the intervention group was $52.8 \%$ compared with $26.5 \%$ in the control group. However, unlike in our study, these authors did not show that this increase in the vaccination of physicians led to increased vaccination of their patients.

\section{Conclusions}

Our results show that vaccination of primary care physicians was a minor determinant of the vaccination coverage of their patients aged $\geq 65$ years, but remained statistically-significant after controlling for other potential effects associated with the physician's knowledge, attitudes and beliefs on influenza vaccination. Moreover, influenza vaccination was also associated with favorable opinions about vaccination. Therefore, the promotion of influenza vaccination of primary care physicians through improving their opinions and attitudes about influenza vaccination may have a beneficial effect on vaccination coverages in their patients. Interventional studies to increase influenza vaccination of primary care physicians in order to determine whether this leads to increased vaccination coverages in their patients aged $\geq 65$ years are warranted.

\section{Additional file}

Additional file 1: Table S1. Characteristics of early and late responders among primary healthcare physicians and influenza vaccine coverage in their patients aged $\geq 65$ years. Table $\mathbf{S 2}$. Influenza vaccine coverage in persons aged $\geq 65$ years in Spanish regions participating or not in the study.

\section{Competing interests}

The authors declare that they have no competing interest.

\section{Authors' contributions}

AG, PG, JMM, VM, JA, NT, FGC, SG, JDB, ST participated in the design and the sample of study. AD, DT and NS performed the pilot study. AG, PG, JMM, VM, JA, NT, FGC, SG, JDB, ST implemented the study and gathered epidemiological information. AD, DT and NS performed the statistical analysis. PG, AD, JC prepared the draft of the manuscript and all authors made relevant contributions to successive versions. All authors read and approved the final manuscript.

\section{Acknowledgements}

The other members of the CIBERESP Working Group for the Survey on Influenza Vaccination in Primary Health Care Workers are:

Jordi Alonso (Institut Municipal de Investigació Mèdica, Barcelona and CIBERESP), Maretva Baricot (CIBERESP), Joan Caylà and Sara Lafuente (Agencia de Salut Pública de Barcelona), Manuel García Cenoz, Iván Martínez Baz (Instituto de Salud Pública de Navarra, Pamplona), José María Quintana (Unidad de Investigación, Hospital Galdakao-Usansolo), Amaia Bilbao González (Unidad de Investigación, Hospital Basurto).

This study was supported by the Ministry of Science and Innovation, Institute of Health Carlos III, Programme of Research on Influenza A/H1N1 (Grant GR09/0030), and the Catalan Agency for the Management of Grants for University Research (AGAUR Grant number 2014/ SGR 421403). The funders had no role in the study design, data collection, analysis, the decision to publish or the preparation of the manuscript.

\section{Author details}

${ }^{1}$ Agencia de Salud Pública de Cataluña, Barcelona, Spain. ${ }^{2}$ CIBER Epidemiología y Salud Pública (CIBERESP), Barcelona, Spain. ${ }^{3}$ Instituto de Investigación Biomédica de Lleida, Universidad de Lleida (IRBLleida), Lleida, Spain. ${ }^{4}$ Instituto de Salud Pública de Navarra, Pamplona, Spain. ${ }^{5}$ Servicio de Vigilancia de Andalucía, Sevilla, Spain. ${ }^{6}$ Instituto de Biomedicina, Universidad de León, León, Spain. ${ }^{7}$ Área de Epidemiología, Comunidad de Madrid, Madrid, Spain. ${ }^{8}$ Departamento de Salud Pública, Universidad de Barcelona, Barcelona, Spain. ${ }^{9}$ Servicio de Epidemiología, Agencia de Salud Pública de Barcelona, Barcelona, Spain. ${ }^{10}$ Centro Superior de Investigación en Salud Pública, Universidad de Valencia, Valencia, Spain. ${ }^{11}$ Unidad de Investigación, Hospital Galdakao-Usansolo, Guipúzcoa, Spain. ${ }^{12}$ Servicio Andaluz de Salud, Sevilla, Spain. ${ }^{13}$ Dirección General de Salud Pública, Investigación, Desarrollo e Innovación, Junta de Castilla y León, León, Spain.

Received: 19 November 2014 Accepted: 19 March 2015 Published online: 31 March 2015

\section{References}

1. Fiore $A E$, Uyeki $T M$, Broder $K$, Finelli $L$, Euler $G L$, Singleton JA, et al. Prevention and control of influenza with vaccines: recommendations of the Advisory Committee on Immunization Practices (ACIP), 2010. MMWR Recomm Rep. 2010;59(RR-8):1-62.

2. World Health Organization. Influenza fact sheet. WER. 2003;78(11):77-80,

3. Picazo J, Suárez A, Fernández A, Rodríguez B, Villorejo S, del Amo MP, et al. Consenso sobre la vacunación frente a la gripe en el personal sanitario. Rev Esp Quimioter. 2012;25:226-39.

4. Bautista D, Vila B, Usó R, Téllez M, Zanón V. Predisposing, reinforcing, and enabling factors influencing influenza vaccination acceptance among healthcare workers. Infect Control Hosp Epidemiol. 2006;27(1):73-7.

5. Elorza Ricart JM, Campins Marti M, Martinez Gomez X, Allepuz Palau A, Ferrer Gramunt E, Mendez-Aguirre GM. Influenza vaccine and health-care workers: strategies to achieve compliance in a tertiary hospital. Med Clin (Barc). 2002;119(12):451-2.

6. Galicia-Garcia MD, Gonzalez-Torga A, Garcia-Gonzalez C, Fuster-Perez M, Garrigos-Gordo I, Lopez-Fresnena N, et al. Influenza vaccination in 
healthcare workers. Why are some vaccinated whereas others are not. Enferm Infecc Microbiol Clin. 2006;24(7):413-7.

7. Jiménez-García R, Hernández-Barrera V, Carrasco-Garrido P, López de Andrés A, Pérez N, de Miguel ÁG. Influenza vaccination coverages among children, adults, health care workers and immigrants in Spain: related factors and trends, 2003-2006. J Infect. 2008;57(6):472-80.

8. Vaux S, Van Cauteren D, Guthmann J, Le Strat Y, Vaillant V, de Valk H, et al. Influenza vaccination coverage against seasonal and pandemic influenza and their determinants in France: a cross-sectional survey. BMC Pub Health. 2011;11(1):30.

9. Arda B, Durusoy R, Yamazhan T, Sipahi OR, Taşbakan M, Pullukçu H, et al. Did the pandemic have an impact on influenza vaccination attitude? A survey among health care workers. BMC Infec Diseases. 2011;11(1):87.

10. Dedoukou X, Nikolopoulos G, Maragos A, Giannoulidou S, Maltezou HC. Attitudes towards vaccination against seasonal influenza of health-care workers in primary health-care settings in Greece. Vaccine. 2010;28(37):5931-3.

11. Kraut A, Graff L, McLean D. Behavioral change with influenza vaccination: Factors influencing increased uptake of the pandemic H1N1 versus seasonal influenza vaccine in health care personnel. Vaccine. 2011;29(46):8357-63.

12. Nichol K, Margolis K, Wuorenma J, Von Sternberg T. The efficacy and cost effectiveness of vaccination against influenza among elderly persons living in the community. N Engl J Med. 1994;331(12):778-84.

13. Govaert TM, Thijs C, Masurel N, Sprenger M, Dinant G, Knottnerus J. The efficacy of influenza vaccination in elderly individuals. JAMA. 1994;272(21):1661-5.

14. Abramson Z, Cohen-Naor V. Factors associated with performance of influenza immunization among the elderly. Isr Med Assoc J. 2000;2(12):902-7.

15. Evans MR, Watson PA. Why do older people not get immunised against influenza?: A community survey. Vaccine. 2003;21(19):2421-7.

16. Frank E, Breyan J, Elon L. Physician disclosure of healthy personal behaviors improves credibility and ability to motivate. Arch Fam Med. 2000;9(3):287.

17. Abramson $\mathrm{ZH}$, Levi $\mathrm{O}$. Influenza vaccination among primary healthcare workers. Vaccine. 2008;26(20):2482-9.

18. Abramson ZH, Avni O, Levi O, Miskin IN. Is the influenza vaccination rate of elderly patients affected by raising the vaccination rate of the staff at their primary health care clinics? Isr Med Assoc J. 2011;13(6):325-8.

19. Poland GA. The 2009-2010 influenza pandemic: effects on pandemic and seasonal vaccine uptake and lessons learned for seasonal vaccination campaigns. Vaccine. 2010;28 Suppl 4:D3-13.

20. Nougairède A, Lagier J, Ninove L, Sartor C, Badiaga S, Botelho E, et al. Likely correlation between sources of information and acceptability of $\mathrm{A} / \mathrm{H} 1 \mathrm{~N} 1$ swine-origin influenza virus vaccine in Marseille, France. PLOS ONE. 2010:5(6):e11292

21. Mereckiene J, Cotter S, Nicoll A, Lopalco P, Noori T, Weber JT, et al. Seasonal influenza immunisation in Europe. Overview of recommendations and vaccination coverage for three. Euro Surveill. 2014;19(16):20780.

22. Von Elm E, Altman DG, Egger M, Pocock SJ, Gøtzsche PC, Vandenbroucke JP. The Strengthening the Reporting of Observational Studies in Epidemiology (STROBE) statement: guidelines for reporting observational studies. J Clin Epidemiol. 2008;61:344-9.

23. Sarría-Santamera A, Timoner J. Influenza vaccination in old adults in Spain. Eur J Public Health. 2003;13(2):133-7.

24. Sarría-Santamera A, Sandín-Vázquez M. Vacuna de la gripe: seguimos publicando, pero no mejoramos las coberturas. Gac Sanit. 2008;22(3):291.

25. Coberturas de Vacunación. Datos estadísticos. Ministerio de Sanidad, Política Social e Igualdad. https://www.msssi.gob.es/profesionales/saludPublica/ prevPromocion/vacunaciones/coberturas.htm. Accessed 15 Jan 2015

26. Nichol KL, Hauge M. Influenza vaccination of healthcare workers. Infect Control Hosp Epidemiol. 1997;18:189-94.

27. Kaboli F, Astrakianakis G, Li G, Guzman J, Naus M, Donovan T. Influenza vaccination and intention to receive the pandemic $\mathrm{H} 1 \mathrm{~N} 1$ influenza vaccine among healthcare workers of British Columbia, Canada: a cross-sectional study. Infect Control Hosp Epidemiol. 2010;31(10):1017-24.

28. Chor JS, Pada SK, Stephenson I, Goggins WB, Tambyah PA, Clarke TW, et al. Seasonal influenza vaccination predicts pandemic H1N1 vaccination uptake among healthcare workers in three countries. Vaccine. 2011;29(43):7364-9.

29. Frank E, Rothenberg R, Lewis C, Belodoff BF. Correlates of physicians' prevention-related practices: findings from the Women Physicians' Health Study. Arch Fam Med. 2000;9(4):359.
30. Abramson ZH, Levi O. Is performance of influenza vaccination in the elderly related to treating physician's self-immunization and other physician characteristics? Prev Med. 2008;47(5):550-3.

31. Maltezou HC, Maragos A, Katerelos P, Paisi A, Karageorgou K, Papadimitriou $T$, et al. Influenza vaccination acceptance among health-care workers: a nationwide survey. Vaccine. 2008;26(11):1408-10.

32. Esposito S, Bosis S, Pelucchi C, Tremolati E, Sabatini C, Semino M, et al. Influenza vaccination among healthcare workers in a multidisciplinary University hospital in Italy. BMC Public Health. 2008;8(1):422.

33. Leitmeyer K, Buchholz U, Kramer M, Schenkel K, Stahlhut H, Köllstadt M, et al. Influenza vaccination in German health care workers: effects and findings after two rounds of a nationwide awareness campaign. Vaccine. 2006;24(47):7003-8.

34. Clark SJ, Cowan AE, Wortley PM. Influenza vaccination attitudes and practices among US registered nurses. Am J Infect Control. 2009;37(7):551-6.

35. Kok G, van Essen GA, Wicker S, Llupià A, Mena G, Correia R. Planning for influenza vaccination in health care workers: an Intervention Mapping approach. Vaccine. 2011;29:8512-9.

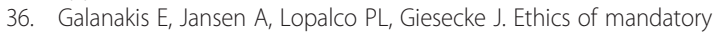
vaccination for healthcare workers. Euro Surveill. 2013;18(45):20627.

37. Rebmann T, Wright KS, Anthony J, Knaup RC, Peters EB. Seasonal influenza vaccine compliance among hospital-based and nonhospital-based healthcare workers. Infect Control Hosp Epidemiol. 2012;33:243-9.

38. Lehmann B, Ruiter R, van Dam D, Wicker S, Kok G. Sociocognitive predictors of the intention of healthcare workers to receive the influenza vaccine in Belgian, Dutch and German hospital settings. J Hosp Infect. 2014; doi: 10.1016/j.jhin.2014.11.009.

39. Looijmans-van den Akker I, van Delden JJ, Verheij TJ, van der Sande MAV, Essen GA, Riphagen-Dalhuisen J, et al. Effects of a multi-faceted program to increase influenza vaccine uptake among health care workers in nursing homes: A cluster randomised controlled trial. Vaccine. 2010;28:5086-92.

40. Lemaitre M, Meret T, Rothan-Tondeur M, Belmin J, Lejonc J, Luquel L, et al. Effect of influenza vaccination of nursing home staff on mortality of residents: a cluster-randomized trial. J Am Geriatr Soc. 2009;57(9):1580-6.

\section{Submit your next manuscript to BioMed Central and take full advantage of:}

- Convenient online submission

- Thorough peer review

- No space constraints or color figure charges

- Immediate publication on acceptance

- Inclusion in PubMed, CAS, Scopus and Google Scholar

- Research which is freely available for redistribution 